\title{
The Effect of Law Changes on the Lineout In Rugby Union with regards to the Six Nations, Tri Nations, European Cup And Super 12 Competitions from 1999 to 2003.
}

Jason Williams*

\begin{abstract}
Any sporting event is defined and played within a framework of rules. Once defined, they rarely remain the same, mutating in response to the dynamic pressures generated by the various participants. Rugby union has undergone a many rule changes in the game and has rich potential for investigation of of rule related variables. This paper investigated the effect of these changes with reference to the Six Nations Tri Nations, European Cup and Super 12 competitions $(n=496)$ over a period of 5 years, between 1999 and 2003. Data captured from the year preceding the rule change (1999) was compared with the four following years. Using Kruskal-Wallis it was found that there were a number of significant differences $(H<.01)$ in the data. Further analysis was undertaken using a post-hoc application of a Mann-Whitney to test significance. The introduction of the new rules introduced positive aspects to the lineout in terms of increased competition. In addition to changes within the data, there appeared a number of themes in terms of differences between groups in the way the rule changes were accepted; unexpected outcomes from rule changes and finally consistent patterns in the data that could be related dynamical systems.
\end{abstract}

\section{Introduction}

A ny sporting event is defined and played within a framework of laws. Once defined, they rarely remain the same, mutating in response to the dynamic pressures generated by the various participants and stakeholders (Kew 1986; 1987). Rugby union has undergone a number of law changes in the game, especially with its transition from the amateur to professional code in 1995 and has rich potential for investigation of law related variables. In 1999, the International Rugby Board introduced a number of law changes with regards to the lineout in rugby union after much discussion by commentators on the problems within the game (McRae, 1998; Davies 1999).

\footnotetext{
*BSc(Hons) PhD MBCS FHEA, Programme Director of Computing and Information Systems, Information Systems and International Studies Department, Cardiff School of Management, University of Wales Institute Cardiff.
}

Some of these changes directly influenced the lineout and it is hypothesised that there were other changes to the laws of the game that all also influenced the lineout. Currently, research into law changes have been limited to pre and post law change or non specific references have been made to law changes that were associated to the particular study. This paper aims to examine the effect of law changes over time and will investigate the changes within the lineout with regards to game play through analysing the Six Nations, Tri Nations, European Cup and Super 12 competitions from 1999 to 2003 and will build on earlier work by Williams et al, 2003; 2005; 2006. The above analysis will not only permit comparisons between competitions, but also between hemisphere, level of competition and will permit investigations into any themes that emerge from the research. 


\section{Background}

To date there have been a number of studies into why and how laws change in sport. For example, Kew (1987) stated that games such as basketball, hockey and different codes of football change their laws frequently, but little is known of the forces that impel such changes. Gardiner et al., (1998) argued that law changes are merely tinkering and are often carried out with the aim of short-term expediency, often to placate external pressures such as sponsors and television. Hammond et al., (1999) and their work on netball attributed law changes to three main factors: player performance, technological advancement and commercial pressures. Research such as this illustrate how complex the process of changing laws can be, and underpins the creation of categories for the classification of law changes as discussed below.

Laws may change in a game either due to safety, the natural development and progression that occurs in a game and external forces such as entertainment, commercial and media pressures. Hackney (1994) highlighted a number of issues relating to player safety and discussed how to prevent and manage injuries in sport through the importance of adhering to the given laws. Parkkari et al., (2001) argued that in every sport they examined, law changes were imperative to player safety and should be constantly examined to ensure this continued. The natural progression of a game is governed by improved training and support, the speed and physique of the participants (Norton et al., 1999; Olds, 2001), testing and pressuring the laws (Loland, 1998) and changes to the equipment used (Haake et al., 2000). Finally, the effect of entertainment, commercial and pressures from the media have an influence on why laws change within sport. Cousens (1997) documented the explosion in revenue gained from television contracts with American sports and suggested that the media had some control of the game itself. Tyrrell (1980) conducted research into baseball and argued that once large sums of money had been invested, the need for a quicker and a more exciting game intensified and demands were placed on the game in order to make it so. These are all pressures that are placed on a sport and have a part in its evolution.

Notational analysis may be used to gauge the effect of law changes over time and this has been undertaken in a number of sports. Doggart et al., (1993) used a hand notation system to notate and analyse the time saved by the law changes and the specific aspects of play that contributed to the changes in playing time and discovered that the time that the ball in play time increased by $2 \%$. Hughes and Sykes (1994) analysed the effects of the 1992 back-pass law in soccer and found that there were significantly fewer back-passes to the goalkeeper as a form of time wasting and that the goalkeeper had less possession of the ball. Hughes (1995) examined a new scoring system that was introduced by the Squash Rackets Association in an attempt to make the game more attractive to viewing audiences and found that that there was no significant difference between the two scoring systems. Howells (2000) investigated the oneday game of cricket and the effect of introducing a 30-yard circle that all except two fielders were positioned and found that the game was more exciting. These examples briefly illustrate the type of information that can be gained from studying the effect of law changes through notational analysis.

A number of studies specific to rugby union have been conducted with regards to why laws change. Safety was a factor that was researched by Silver (1992), who found that that there was a reduction in the number of injuries in rugby union, between 1956 to 1982 and 1982 to 1987 , which he attributed to law changes. Natural progression was noted as an influence on law changes within rugby union with the work 
undertaken by Potter and Carter, 1995; Thomas and Williams, 2001. Studies have shown that the speed of the game has placed stress on the laws of the game with an increase in ball in play times and more actions in open play. The effect of commercialisation and the media was recognised by Hutchins and Phillips (1999) who investigated the change in rugby since professionalism and discussed the globalisation of rugby as a product. They recognised that rugby union was now the fourth biggest spectator sport in the world, thus making it an extremely profitable vehicle for advertising and marketing which in turn placed stress on the game administrators to make the game more exciting to watch and play.

In addition to the work undertaken in determining why laws have changed in rugby union, a number of studies have also been conducted into their effects. Hughes and Clarke, (1994) analysed a number of law changes introduced by the IRB in order to make the game more exciting. These changes resulted in more passes per possession but with the same number of tries, which would suggest that the law change was influential in some areas of the game. Potter and Carter (1995) compared the Rugby World Cup Finals in 1991 and 1995 and statistically highlighted the differences between how the game was played in the two competitions and indicated that law changes influenced game play. Hughes et al., (1997) found that that games played by men and women differed greatly, especially in the areas of tackling, rucking, mauling, lineouts and kicking which should be recognised by the game administrators in terms of law change. Research such as this again highlight the importance of ensuring that changes with regards to the laws are monitored effectively using notational analysis.

Little research has been undertaken into gauging the effect of law changes over a number of years. Sports may be altered through changes to the laws, but little is understood about what effect these changes have. Some studies have investigated the effect of law change in different sports and compared sets of data pre and post law change. However, there appears to be limited research that investigates the effect of law change over a number of years. The investigation of the effect of law change on a sport may aid the administrators of the game in the introduction of law changes and may also enable the tracking of their effect after implementation. This paper aims to build upon existing literature through analysis of the variables and processes that impact on the development of laws within a game, including the intended and unintended effect of new laws on the game over time. Rugby union will be used a vehicle for the investigation of law changes, as this sport has undergone a number of changes in the last few years and as discussed earlier, is a sport that has a number of issues regarding its laws. 


\section{Methods}

The type of information captured came from discussion with experts in the field of rugby union and academics in the field of notational analysis. After these discussions, it was agreed to develop the following definitions for the lineout.

Table 1. Definitions of terms used in the study.

\begin{tabular}{|l|l|}
\hline \multicolumn{1}{|c|}{ Term } & \multicolumn{1}{c|}{ Definition } \\
\hline Won/Lost & Immediate possession gained/lost from the lineout. \\
\hline Not Straight & $\begin{array}{l}\text { Lineout ball where the ball was not thrown in straight and called by the } \\
\text { referee. }\end{array}$ \\
\hline Contested ball & The number of lineouts contested by the opposing team. \\
\hline $\begin{array}{l}\text { Penalties/Free Kicks } \\
\text { ForFor }\end{array}$ & $\begin{array}{l}\text { If the referee terminates the lineout for an infringement against the team } \\
\text { not in possession. }\end{array}$ \\
\hline $\begin{array}{l}\text { Penalties/Free Kicks } \\
\text { Against }\end{array}$ & $\begin{array}{l}\text { If the referee terminates the lineout for an infringement against the team in } \\
\text { possession. }\end{array}$ \\
\hline
\end{tabular}

In order to capture the data a specialised piece of software needed to be developed (Figure 1). A number of software packages were investigated, but these were not chosen as they limited control and manipulation of the data (Williams, 2004). The programming language Microsoft Visual Basic (VB) was regarded as the best tool for developing the application as it is an excellent tool for prototyping and database connectivity. The database chosen was Microsoft Access, which is a standard, but powerful database that can be found on most PC based computers.

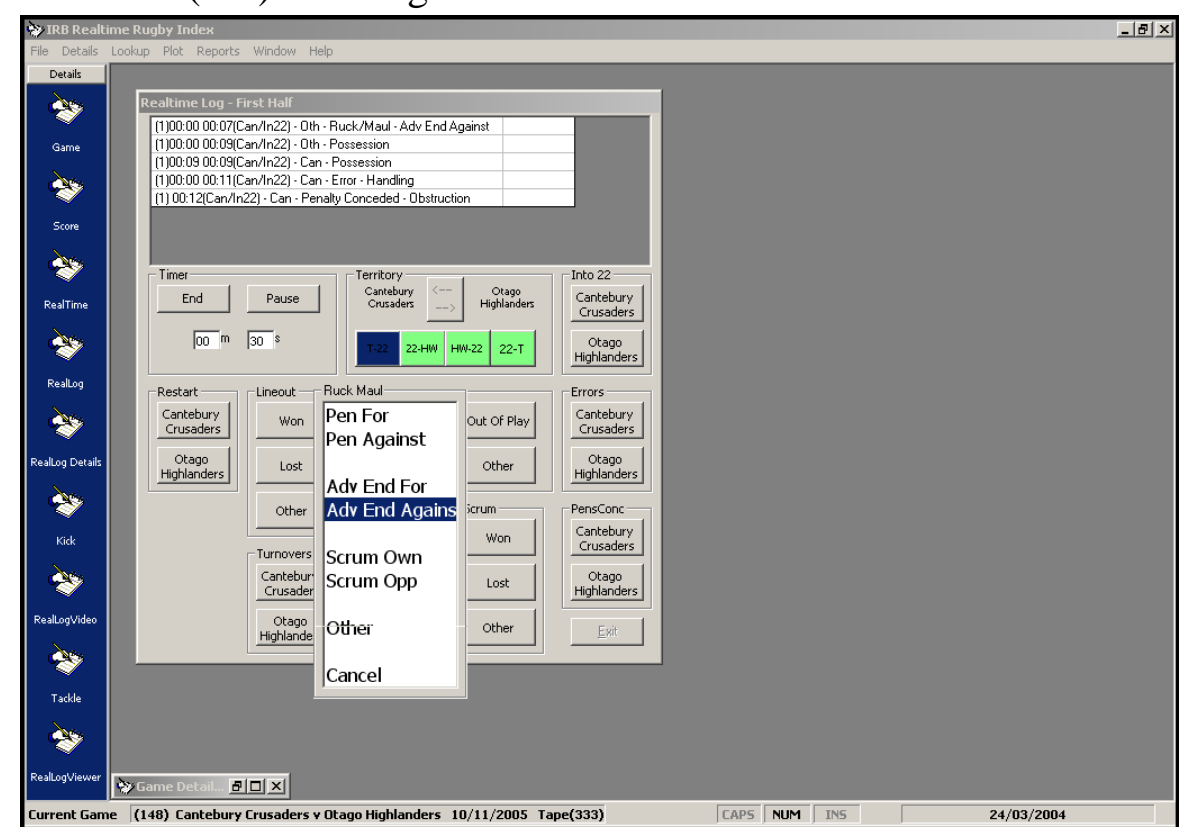

Figure 1. The real-time capture screen 
A reliability study was undertaken using percentage differences and a modified Bland and Altman plot. This method has been considered as a robust method of reliability and has been discussed in detail by Hughes et al., (2002). The system was tested for reliability using percentage differences for intra-operator reliability. This scored error percentages of less than 5\%, which was considered acceptable given the analytical goals of the study.

The time period chosen ranged from 1999 to 2003 and competitions took place in each year. This period was one of significant change within rugby union, with its transformation from amateur professional status. As many games as possible were chosen from each group in order to build a robust normative profile (Hughes et al, 2001), but there were limitations placed on the study as some of the competitions' match footage was difficult to obtain. A selection of games were annotated from the Six Nations $(n=70)$, Tri Nations $(n=30)$, European Cup $(n=88)$ and Super $12(n=288)$ competitions. The aim of this research was to investigate differences between groups which in turn suggest a certain set of statistical procedures. A Kruskal-Wallis test was used to test for significant differences and then interrogated further using a post-hoc application of a MannWhitney test. These tests were considered as being the most powerful for analysis of nonparametric data.

\section{Results}

The following results illustrate the changes in the game that occurred from 1999 to 2003 for the lineout. Each section displays the results with regards to each individual grouping over the five year period. The competitions were placed into groups for analysis and comparison. These were;

All: All games

Northern Hemisphere (NH): Six Nations and European Cup

Southern Hemisphere (SH): Tri Nations and Super 12

International: Six Nations and Tri Nations

Elite Club: European Cup and Super 12

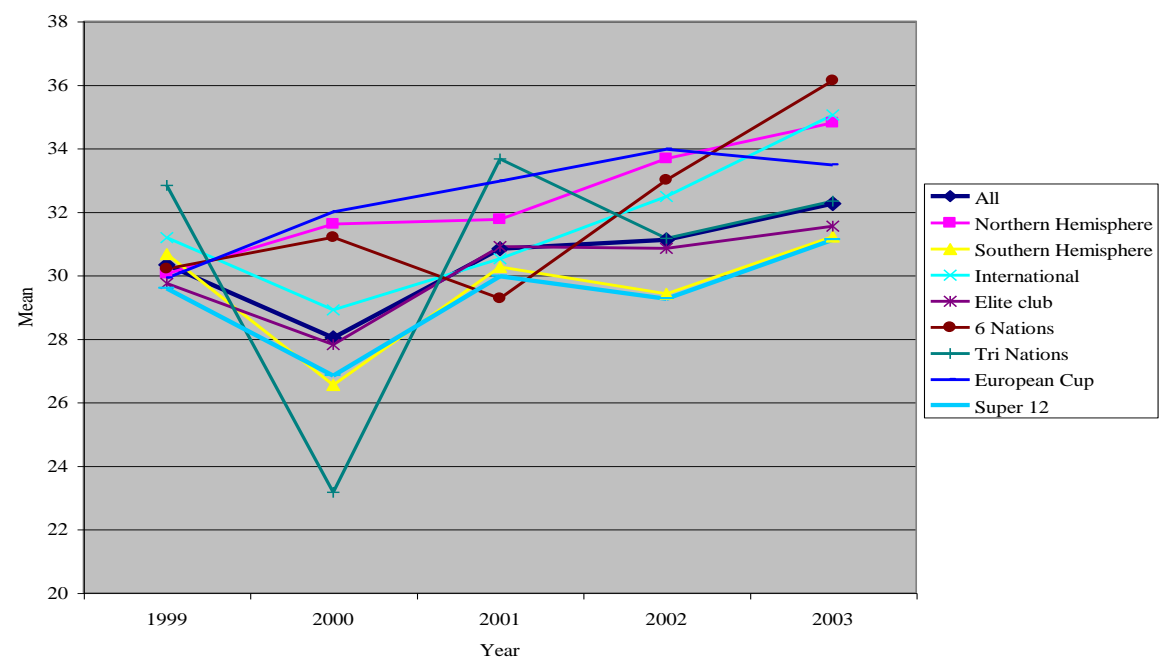

Figure 2. The mean number of lineouts per grouping for each year. 


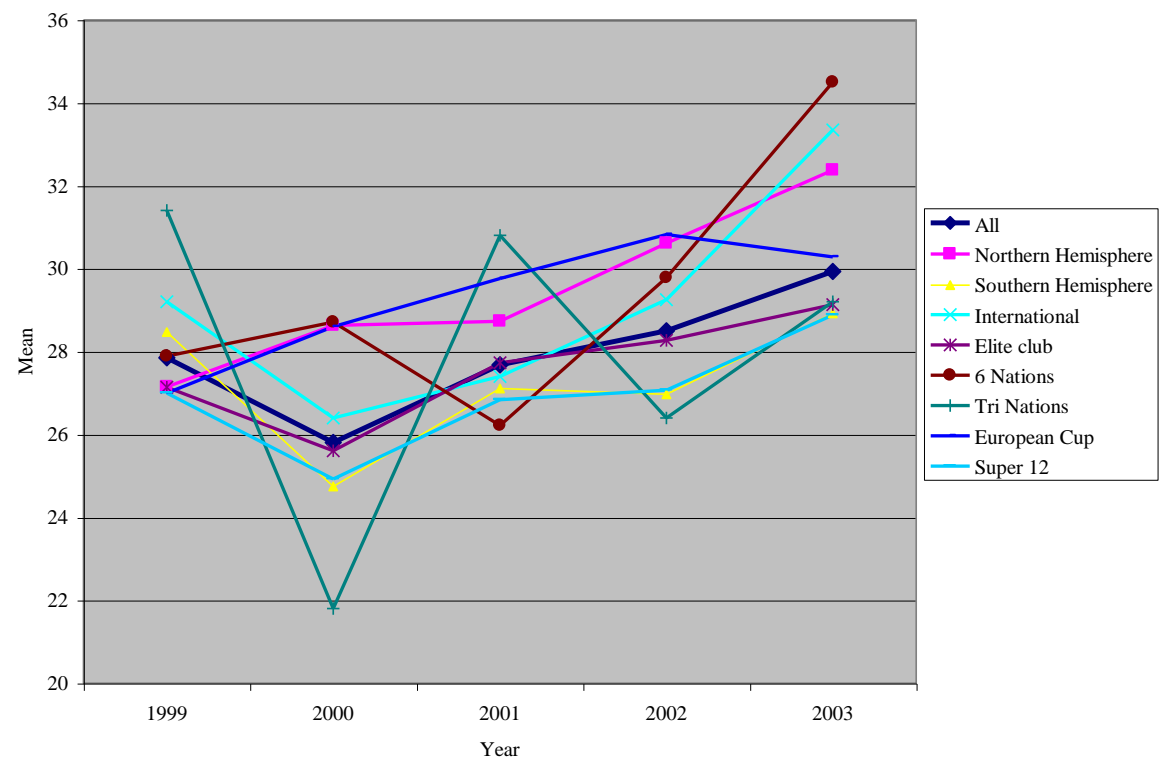

Figure 3. The mean number of contestable lineouts in a game by year and by group.

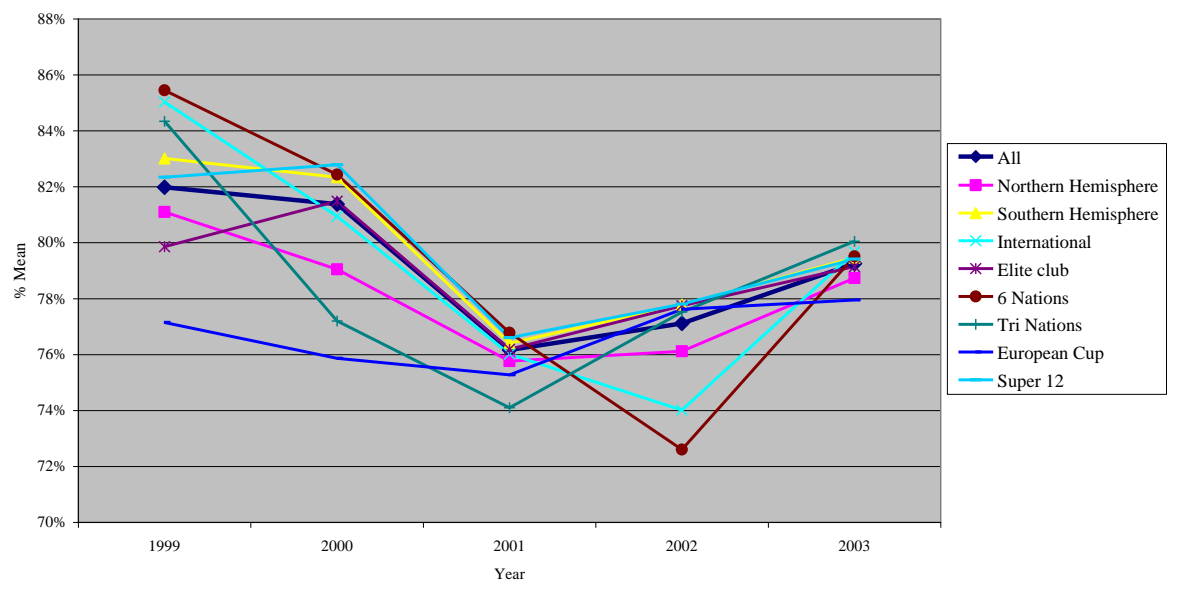

Figure 4. The mean percentage of lineouts won in a game by year and by group.

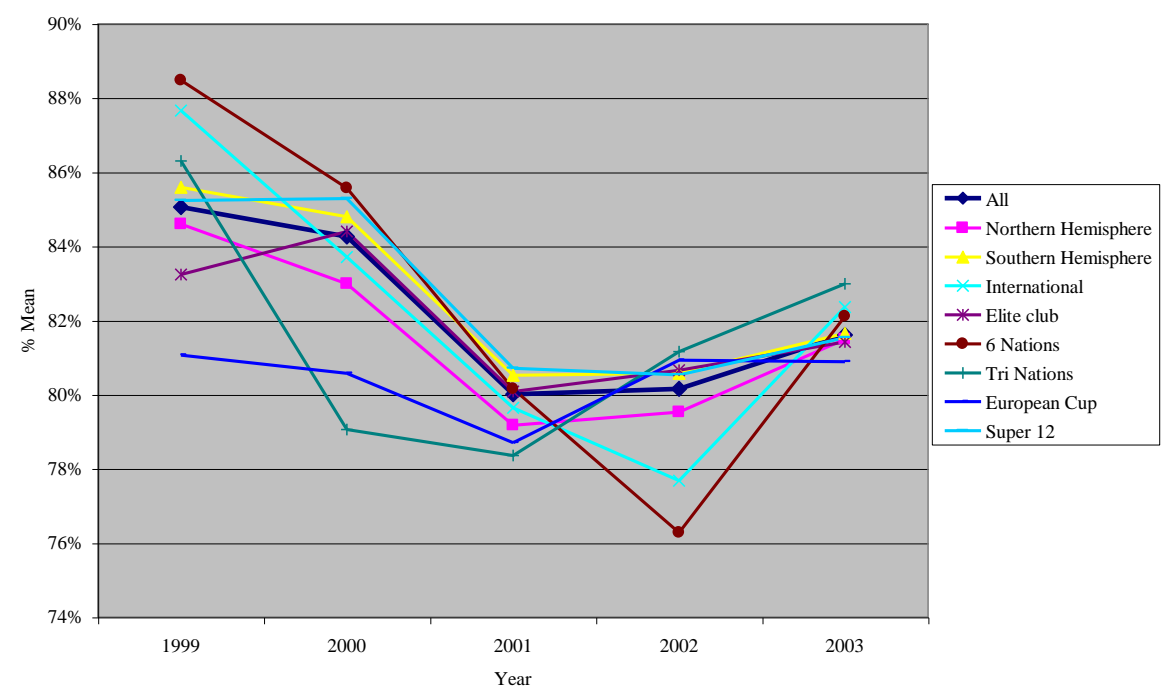

Figure 5. The mean percentage of lineout possession gained by the throwing in team in a game by year and by group. 


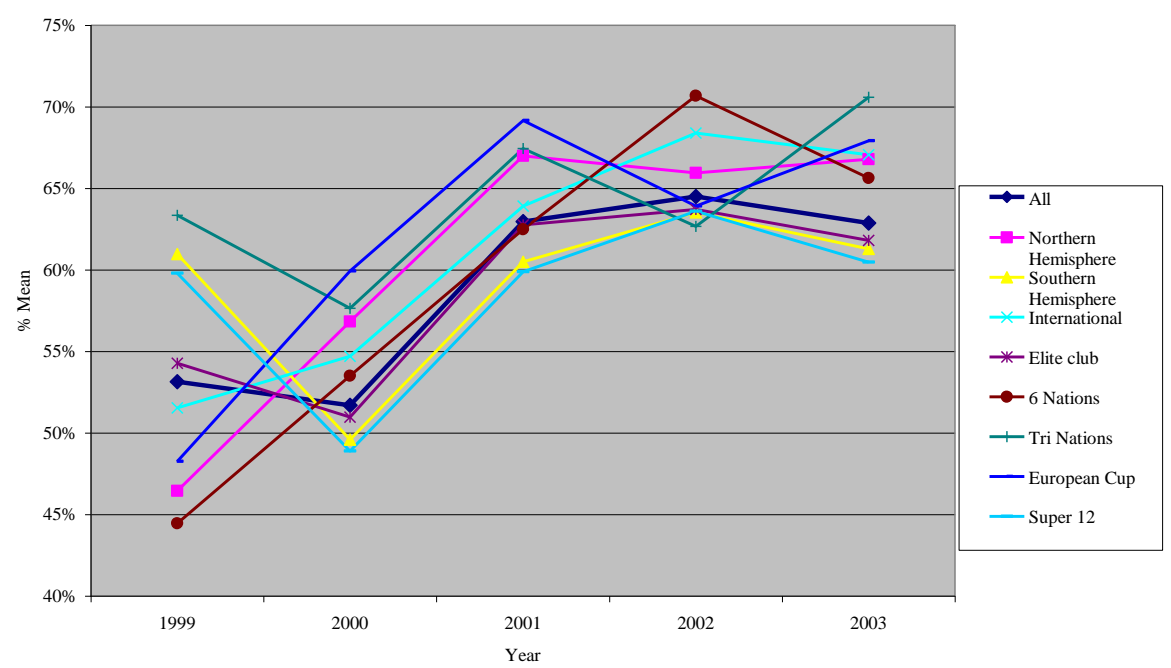

Figure 6. The mean percentage of contested lineouts in a game by year and by group.

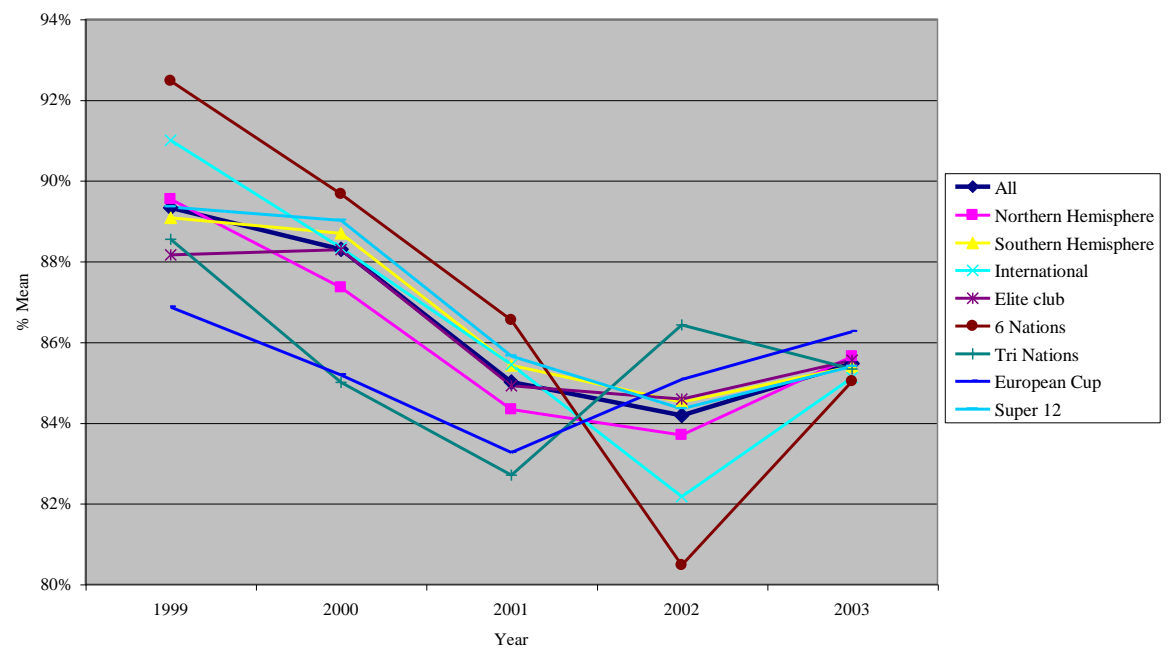

Figure 7. The mean percentage of lineouts won from contestable lineouts in a game by year and by group.

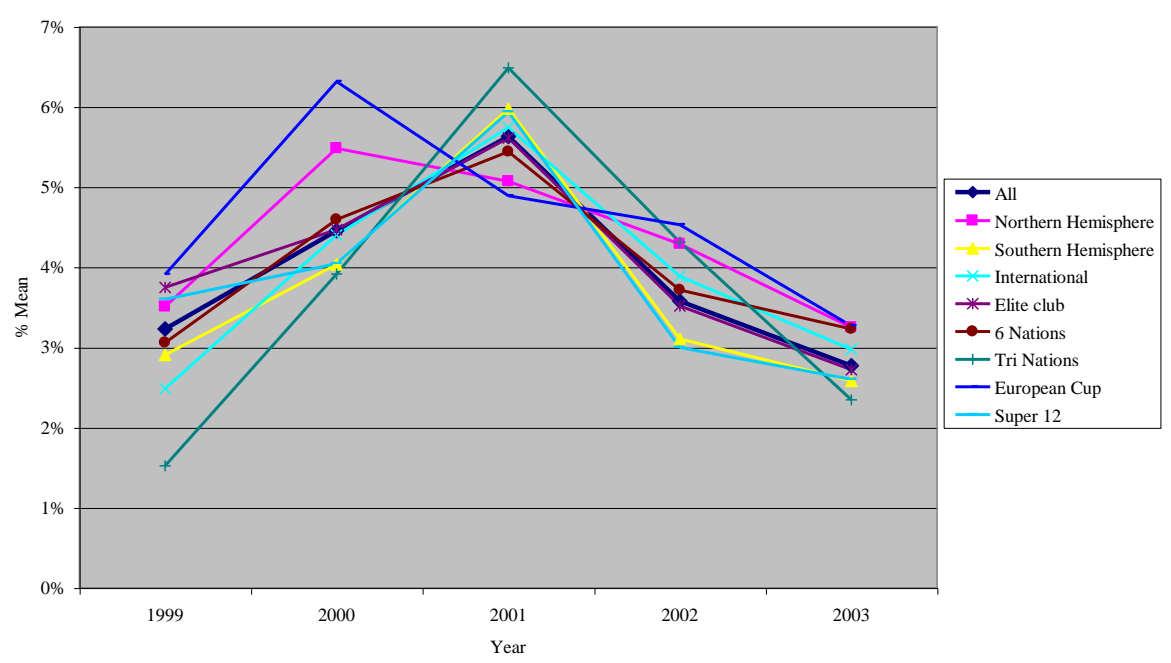

Figure 7. The mean percentage of lineouts penalised from all lineouts in a game by year and by group. 


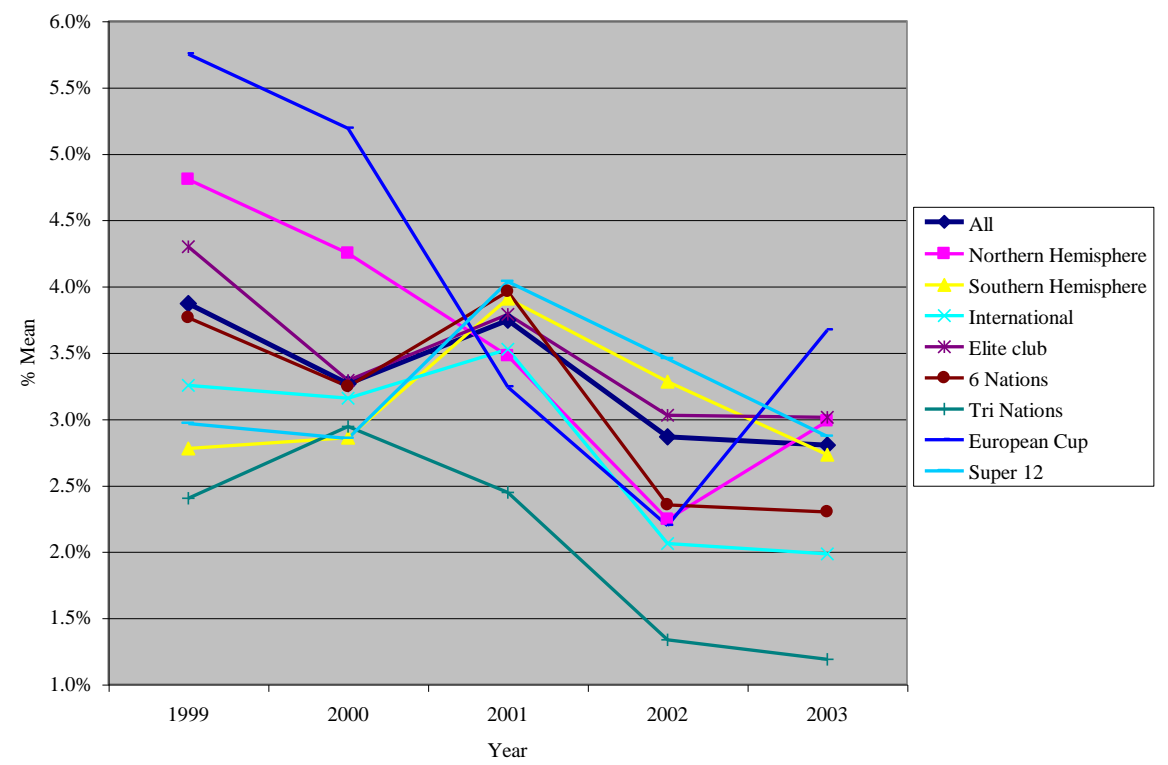

Figure 8. The mean percentage of lineouts not thrown in straight from all lineouts in a game by year and by group.

Table 2. Statistical significance summary of the lineout using Kruskal Wallis.

\begin{tabular}{|c|c|c|c|c|}
\hline Comparisons & $\begin{array}{c}\text { Hemisphere } \\
\text { (NH \& SH) }\end{array}$ & $\begin{array}{c}\text { Level } \\
\text { (International } \\
\text { \& Elite Club) }\end{array}$ & $\begin{array}{c}\text { Competition } \\
(6 \mathrm{~N}, 3 \mathrm{~N}, \mathrm{EC}, \\
\text { S12) }\end{array}$ & $\begin{array}{l}\text { Yearly on All } \\
\text { games }(2000- \\
2003)\end{array}$ \\
\hline 1. Number of lineouts & $* *$ & NS & $* *$ & $* *$ \\
\hline 2. Contestable lineouts & $* *$ & NS & $* *$ & $* *$ \\
\hline 3. Won from all lineouts & $*$ & NS & NS & $* *$ \\
\hline 4. Possession gained & NS & NS & NS & $* *$ \\
\hline 5. Contested lineouts & $*$ & NS & $*$ & $* *$ \\
\hline 6. Contestable lineouts won & NS & NS & NS & $* *$ \\
\hline 7. Penalised & NS & NS & NS & $*$ \\
\hline 8. Not straight & NS & NS & NS & NS \\
\hline
\end{tabular}

* $(\mathbf{P}<\mathbf{0 . 0 5})$

$* *(\mathbf{P}<\mathbf{0 . 0 0 1})$ 
Table 3. Statistical significance summary of the lineout using a post-hoc application of a Mann-Whitney test applied to the competitions.

\begin{tabular}{|l|c|c|c|c|c|c|}
\hline Comparisons & 6N \& 3N & 6N \& EC & 6N \& S12 & 3N \& EC & 3N \& S12 & EC \& S12 \\
\hline 1. Number of lineouts & NS & NS & $*$ & NS & NS & $* *$ \\
\hline 2. Contestable lineouts & NS & NS & $*$ & NS & NS & $* *$ \\
\hline 5. Contested lineouts & NS & NS & NS & NS & $*$ & $* *$ \\
\hline
\end{tabular}

$*(\mathbf{P}<\mathbf{0 . 0 5})$

$* *(\mathbf{P}<\mathbf{0 . 0 0 1})$

Table 4. Statistical significance summary of the lineout using a post-hoc application of a Mann-Whitney test applied to year groupings.

\begin{tabular}{|c|c|c|c|c|c|c|c|c|c|c|}
\hline Comparisons & 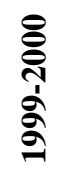 & 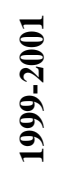 & 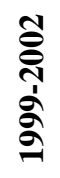 & 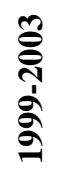 & 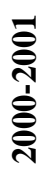 & 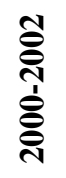 & 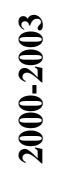 & 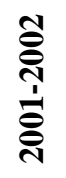 & 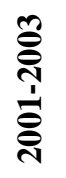 & 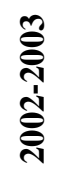 \\
\hline 1. Number of lineouts & NS & NS & NS & NS & $*$ & $*$ & $* *$ & NS & NS & NS \\
\hline 2. Contestable lineouts & NS & NS & NS & $*$ & $*$ & $* *$ & $* *$ & NS & $*$ & NS \\
\hline 3. Won from all lineouts & NS & $*$ & $*$ & NS & $* *$ & $*$ & NS & NS & $*$ & NS \\
\hline 4. Possession gained & NS & $*$ & $*$ & $*$ & $* *$ & $* *$ & $*$ & NS & NS & NS \\
\hline 5. Contested lineouts & NS & $*$ & $* *$ & $* *$ & $* *$ & $* *$ & $* *$ & NS & NS & NS \\
\hline 6. Contestable lineouts won & NS & $*$ & $* *$ & $*$ & $*$ & $* *$ & $*$ & NS & NS & NS \\
\hline 7. Penalised & NS & NS & NS & NS & $*$ & NS & NS & $*$ & $*$ & NS \\
\hline
\end{tabular}

$*(\mathbf{P}<0.05)$

$* *(\mathbf{P}<\mathbf{0 . 0 0 1})$

\section{Discussion}

The lineout underwent a series of law changes in order to improve competition, safety and reduce time wasting. In January 2000, the law on lifting was clarified in order to improve this aspect of the lineout. Additionally, in June 2001 players had to ensure that the jumping player was lowered safely to the ground. Time wasting at the lineout was addressed in April 2002 with the banning of huddles before a lineout, as some teams joined the lineout as a running mass of players. At the same time a law was introduced to ensure that players remained in the lineout until it terminated. This law was established in order to increase space on the pitch by ensuring that all forwards remained in the lineout until it terminated. 
The data for the lineout illustrated differences that occurred over the period of the study. The laws on lifting (January, 2000) and lowering jumpers (June, 2001) appeared to have a significant effect on nearly all areas of analysis. The changes in the lineout occurred just after these lineout laws were introduced and resulted in a period of rapid decrease or increase in the data. However, the initial change in the data were not as vigorous in the latter years as the new laws were accepted after an initial period of acclimatisation. There appeared to be a change in the data after the new lineout laws had been introduced.

The frequency of lineouts increased over the period of the study, which may have been due to increased competition and improved continuity at the breakdown. If a team could compete more at the lineout, then kicking the ball for territory could be supported by an increased chance of retaining possession. The improved continuity from the breakdown may have introduced more kicking or different tactics into the game. There also appeared to be more competition and more aggression towards the introduction of the new lineout laws in the Northern Hemisphere. More lineouts were contested, less possession was won and more pressure may have been placed on the lineout thrower because of the increased competition, especially in the Northern Hemisphere. However, the rate of penalties at the lineout remained constant with little difference between groups and competitions.

Overall, the introduction of the new laws regarding lifting and lowering introduced positive aspects to the lineout in terms of increased competition which meant that the team throwing the ball in had less chance of maintaining possession of the ball at the lineout. Initial reactions in the data to the new laws were turbulent, but then settled and were accepted in a positive manner. Laws that banned the huddle and stated that players should remain in the lineout until it ended, did not register a change within the lineout data, but may have contributed to changes in other areas of the game, such as increased ball in play.

In addition to highlighting the changes within the game, a number of themes emerged from the data. These included differences between groups, especially between the Northern and Southern Hemisphere competitions. They ranged from initial differences in the first few years to the movement of data and frequency of actions. The disparity between hemispheres was more explicit than the difference between the levels of competition. The Northern Hemisphere tended to be more aggressive in the way that they addressed the changes and they saw the lineout as an area for competition. The Southern Hemisphere were more positive in their attitude to the changes as their appeared to be a more positive approach in the way the changes were dealt with. The research also recognised that there were some discrepancies in the way the law changes were received by International and Elite Club teams. Although the differences between the two groups were not as stark as the differences between hemispheres.

Law makers also need to be aware of the dangers of looking at one particular set of data or only at one group of games in order to gauge the effect of a law change. The data shown here has illustrated stark differences between groups and competitions. If data was viewed as one group, then many of the findings of this research would have masked the way groups reacted. Sports administrators should recognise that the objective measurement of changes within the game need to be done with a number of groups in order to recognise any changes in game play. Further, the reaction to the law change was illustrated only in the top International games and the level below. Future research could highlight further problems with other groups 
and competitions that may have more adverse reactions to a change.

In addition to the expected changes in the lineout, there were also changes that the authorities may not have perceived would happen. The different ways that the hemispheres responded to the law change regarding lifting was one such example. There was an increase in the amount of competition in the lineout, but at the same time there was a significant increase in lineouts that terminated with an infringement.

Changes to the laws of a game can introduce ramifications that can have knock on effects within a number of different areas.

Finally, there appeared to be a period of settling after a law had been introduced. When a change occurred there was an increase or a decrease which was either followed by stagnation in the data or a return to a similar value. There appeared to be a reaction, followed by some form of acceptance, whether it was positive or negative. Sport administrators should be aware that when changes are introduced into a sport they cause an effect and the game changes accordingly. It should also be noted then when the new laws are accepted the change can either stay at the level that the administrators want or don't want. Additionally, the changes can also return to the values that there were originally, thus eliminating the effect of the original law change.

\section{Conclusion}

Law changes in sport need to be objectively measured in some way in order to gauge what happened after a change and also to recognise what is currently happening. This research has recognised a number of changes in the lineout after law changes and found that there are differences in the way teams react to a change depending on the competition, level and hemisphere. The changes that are introduced can be expected and unexpected and have ramifications that can alter unanticipated areas of the game. Any changes should be gradually implemented and these should then be measured to gauge their effect. It was also recognised that when law changes are introduced they can either change the game or simply create an imbalance in the game and then return to the original state. Future research could correlate the findings of this work with other areas of the game or other sports to determine the effect of law change.

\section{References}

Cousens, L. (1997), From diamonds to dollars: The dynamics of change in AAA

baseball franchises. Journal of Sports Management, 11, 316-334.

Doggart, L., Keane, S., Reilly, T., and Stanhope, J. (1993), A task analysis of Gaelic

Football. In: T. Reilly, J. Clarys and A. Stibbe, (Eds.), Science and Football II. London: E. \& F.N. Spon, pp. 186-189.

Davies, G. (1999), Screen tests could turn off rugby's faithful supporters, The Times,

December 3, p.60.

Gardiner, S., Felix, A., James, M., Welch, R. and O'Leary, J. (1998), Sports Law.

London: Cavendish Publishing.

Hackney, R.G. (1994), ABC of sports medicine nature, prevention and management

of injury in sport. British Medical Journal, 308, 1356-1359.

Hammond, J., Hosking, D. and Hole, C. (1999), An exploratory study of the

effectiveness of rule changes in netball. Communications to the Fourth International Conference on Sport. Journal of Sport Sciences, 17, 916-917. 
Haake, S.J., Chadwick, S.G., Dignall, R.J., Goodwill, S. and Rose, P. (2000),

Engineering Tennis - Slowing the game down. Sports Engineering, 3(2), 131-143.

Howells, C. (2000), A comparison of the tactics used by three groups of teams in the

first 15 overs of the 1999 cricket World Cup. Unpublished dissertation, B.Sc. Sport

and Exercise Science, ${ }_{2}$ Cardiff.

Hutchins, B. and Phillips, M. (1999), The global union: Globalisation and the rugby world cup. In: T.J.L Chandler and J. Nauright Making the rugby world. Race, gender and commerce. London: Frank Cass, pp. 149-164.

Hughes, M. (1995), Using notational analysis to create a more exciting scoring system

for squash. In: G. Atkinson and T.Reilly, (Eds.) Sport, Leisure and Ergonomics.

London: E. \& F. N. Spon., pp. 243-247.

Hughes, M. \& Clarke, S. (1994), Computerised notation analysis of rugby union to

examine the effects of law changes upon the patterns of play by international

teams. Journal of Sport Sciences._12(2), 180.

Hughes, M. and Sykes,I.(1994), Computerised notational analysis of the effects of the

law changes in soccer upon patterns of play. Journal of Sport Sciences, 212(1), 180.

Hughes, M., Cooper, S-M. and Nevill, A. (2002), Analysis procedures for non-

parametric data from performance analysis. International Journal of

Performance Analysis in Sport, 2(1), 6-20.
Hughes, M., Evans, S. and Wells, J. (2001), Establishing Normative profiles in

Performance Analysis. eIJPAS, 1, 4-27.

Hughes, M., Kitchen, S. and Horobin, A. (1997), An Analysis of Women's

International Rugby Union. In: M. Hughes, (Ed.), Notational Analysis of Sport

I \& II. UWIC, Cardiff, pp. 125-134.

Jones, M.P., Mellalieu, S.D. and James, N. (2004), Team performance indicators as a

function of winning and losing in rugby union. International Journal of

Performance Analysis in Sport, (1), 61-71.

Kew, F. (1986), Playing the game: An ethnomethodological perspective. International

Review for the Sociology of Sport. 21(4), 305321.

Kew, F. (1987), Contested rules: An explanation of how games change. International Review for the Sociology of Sport, 22(2), 125135.

Loland, S. (1998), Fair Play: historical anachronism or topical ideal?, In: M.J.

McNamee and S.J. Parry, (Eds.), Ethics and Sport. London: E \& FN Spon, pp. 57-64.

McRae, D. (1998), Winter Colours, Changing Seasons in World Rugby. London:

Mainstream Publishing Company.

Norton, K., Schwerdt, S. and Lange, K. (2001),

Evidence for the aetiology of injuries

in Australian football. British Journal of Sport Medicine, 35, 418-423. 
Olds, T. (2001), The evolution of physique in male rugby union players in the

twentieth century. Journal of Sports Sciences, 19, 253-262.

Parkkari, J., Kujala, U.M and Kannus, P. (2001), Is it possible to prevent sports

injuries? Sports Medicine, 31(14), 985-995.

Potter, G. (1997b), A case study of England's performance in the five nations

championship over a five year period. In: $\mathrm{M}$. Hughes, (Ed.), Notational

Analysis of Sport I \& II. UWIC, Cardiff, pp. 193-202.

Potter, G. and Carter, A. (1995), The four year cycle: A comparison of the 1991 and

1995 rugby world cup finals. In: M Hughes, (Ed.), Notational Analysis of

Sport III. UWIC, Cardiff, pp. 216-219.

Silver, J.R. (1992), Injuries of the spine sustained during rugby. British Journal of

Sports Medicine, 26(4), 253-258.

Thomas, C. and Williams, J. (2001), Mapping the world game. In: M. Hughes and

I.Franks, (Eds.), Proceedings of the $5^{\text {th }}$ World Congress of Performance

Analysis, Sports Science and Computers (PASS.COM). UWIC, Cardiff, pp.

91-110.
Tyrrell, I. (1980), Money and morality: The professionalism of American baseball. In:

R. Cashman and M. McKernan, (Eds.), Sport: Money, Morality and the

Media, Sydney: New South Wales University Press Ltd.

Williams, J.J. (2004) The development of a realtime data capture application for

rugby union. World Congress of Performance Analysis of Sport 6. St Mary's

University College, Belfast, June.

Williams, J.J., Thomas, C., Bown, R. and Jones, N. (2003), The effect of the

wheeled scrum law in rugby union. Fifth World Congress on Science and Football, Lisbon, April

Williams, J.J., Hughes, M., O'Donoghue, P. and Davies, G. (2005), The effect of rule

changes on match and ball in play time in rugby union. International Journal

of Performance Analysis in Sport, 5, 3, $1-11$.

Williams, J.J., Hughes, M., O'Donoghue, P. and Davies, G. (2006), The effect of rule

changes on the scrum in rugby union with regards to the Six Nations, Tri

Nations, European Cup and Super 12 competitions. World Congress of

Performance Analysis of Sport 7. Daniel Berzsenyi College, Szombathely,

Hungary, August. 
